Research article

Open Access

\title{
Cost-utility of an 8-month aquatic training for women with fibromyalgia: a randomized controlled trial
}

\author{
Narcís Gusi ${ }^{1}$ and Pablo Tomas-Carus ${ }^{2}$
}

\author{
${ }^{1}$ Faculty of Sports Sciences, University of Extremadura, Avda. Universidad s/n, 10071 Cáceres, Spain \\ 2Department of Sport and Health. University of Évora, Rua de Reguengos de Monsaraz, No. 44, 7000-727 Évora, Portugal \\ Corresponding author: Narcis Gusi, ngusi@unex.es
}

Received: 30 Sep 2007 Revisions requested: 14 Nov 2007 Revisions received: 7 Dec 2007 Accepted: 22 Feb 2008 Published: 22 Feb 2008

Arthritis Research \& Therapy 2008, 10:R24 (doi:10.1186/ar2377)

This article is online at: http://arthritis-research.com/content/10/1/R24

(c) 2008 Gusi and Tomas-Carus; licensee BioMed Central Ltd.

This is an open access article distributed under the terms of the Creative Commons Attribution License (http://creativecommons.org/licenses/by/2.0), which permits unrestricted use, distribution, and reproduction in any medium, provided the original work is properly cited.

\begin{abstract}
Introduction Physical therapy in warm water has been effective and highly recommended for persons with fibromyalgia, but its efficiency remains largely unknown. Should patients or health care managers invest in this therapy? The aim of the current study was to assess the cost-utility of adding an aquatic exercise programme to the usual care of women with fibromyalgia.
\end{abstract}

Methods Costs to the health care system and to society were considered in this study that included 33 participants, randomly assigned to the experimental group $(n=17)$ or a control group $(n=16)$. The intervention in the experimental group consisted of a 1-h, supervised, water-based exercise sessions, three times per week for 8 months. The main outcome measures were the health care costs and the number of quality-adjusted life-years (QALYs) using the time trade-off elicitation technique from the EuroQol EQ-5D instrument. Sensitivity analyses were performed for variations in staff salary, number of women attending sessions and time spent going to the pool. The cost effectiveness acceptability curves were created using a nonparametric bootstrap technique.
Results The mean incremental treatment costs exceeded those for usual care per patient by $€ 517$ for health care costs and $€$ 1,032 for societal costs. The mean incremental QALY associated with the intervention was 0.131 (95\% Cl: 0.011 to 0.290). Each QALY gained in association with the exercise programme cost an additional $€ 3,947 / \mathrm{QALY}(95 \% \mathrm{Cl}: 1,782$ to 47,000 ) for a health care perspective and $€ 7,878 /$ QALY $(3,559$ to 93,818$)$ from a societal perspective. The curves showed a $95 \%$ probability that the addition of the water-based programme is a cost-effective strategy if the ceiling of inversion is $€ 14,200 /$ QALY from a health care perspective and $€$ 28,300/QALY from a societal perspective.

Conclusion The addition of an aquatic exercise programme to the usual care regime for fibromyalgia in women is cost effective in terms of both health care costs and societal costs. However, the characteristics of facilities (distance from the patients' homes and number of patients that can be accommodated per session) are major determinants to consider before investing in such a programme.

Trial registration Current controlled trials ISRCTN53367487.

\section{Introduction}

Fibromyalgia (FM) is a chronic disorder of widespread pain in combination with tenderness of at least 11 of 18 specific tender points [1]. FM affects approximately $2-3 \%$ of the general population, and more than $90 \%$ of patients are female [2-4]. The average yearly cost (updated to 2005 using a 5\% annual inflation) for service utilization among patients with $F M$ is approximately $€ 4,500$, and the societal cost is $€ 8,960$ [5]. These costs are largely due to the frequent use of medical services such as consultations (approximately 10 per year) and medication, and the health system and societal expenses of disability from work [2,3]. Patients with FM consume health care resources to a similar extent as patients with other chronic diseases such as diabetes mellitus and hypertension
[6]. Patients with FM also incur about twice the health care costs as the general population [7], and are absent from work approximately twice as much as other employees [8].

Studies reported in scientific literature have demonstrated evidence of the benefits of physical therapy on health-related quality of life and fitness $[9,10]$. In particular, physical exercise in warm water has been effective in short-term programmes (less than 6 months) and is highly recommended to reduce pain and minimize mechanical impact during exercise [11-15]. However, in our earlier study of patients with FM we found that most of the gains in health-related quality of life and physical fitness achieved in 12 weeks of water-based exercise were lost after a subsequent similar period of physical inactivity 
$[11,16]$. These findings suggest the need for longer programmes or maintenance programmes, but the effectiveness of such programmes remains unknown.

These programmes must be considered in light of limited health system resources. Health system managers or decision-makers frequently select the treatment strategies based on the lowest cost per quality-adjusted life-year (QALY). Cost utility is the ratio of the incremental effectiveness of one strategy compared to another (e.g. standard medical practice), and is measured in QALYs divided by the incremental cost. To our knowledge, there is no cost-utility or cost-effectiveness study of these exercise programmes for patients with FM.

Cost-effectiveness may be studied from a health service perspective by including the costs to the health care system or from a societal perspective by adding to the health care costs those borne by the patients and society. These additional societal costs include time spent, travel costs, lost work hours, etc. The approach from a health service perspective can help inform decisions about adding services to the current health care system.

The purpose of this study was to assess the cost utility of adding an 8-month, supervised, warm water exercise programme to the usual care of Public Health Service for women with FM.

\section{Materials and methods Recruitment}

The population of the catchment area comprised women who were in a local FM association. Eligible women were those who had FM diagnosed by a rheumatologist in accordance with the diagnostic criteria of the American College of Rheumatology (ACR) [1]. A total of 40 potentially eligible participants responded and sought further information (Figure 1). Once the study protocol was explained, 38 people gave their written informed consent. The following exclusion criteria were applied: history of severe trauma, frequent migraines, peripheral nerve entrapment, inflammatory rheumatic diseases, severe psychiatric illness, other diseases that prevent physical loading, pregnancy, participation in another psychological or physical therapy programme, or engaging in regular physical exercise more than once a week for $30 \mathrm{~min}$ or longer during a 2-week period in the last 5 years. The participants in our study of a 12-week aquatic programme [11] were excluded from the current trial to avoid the influence of re-training. Participants' clinical conditions were checked and a rheumatologist confirmed the diagnosis of FM. After excluding 5 candidates due to their participation in other therapies, 33 female patients, aged 37 to 71 years of age, were selected to participate. They were randomly assigned to either the exercise group (EG; $n=$ 17) or a control group (CG; $n=16$ ). Two patients in the EG failed to attend at least $95 \%$ of the treatment sessions due to personal reasons. Nevertheless, these patients were included in the current study to apply an intent-to-treat analysis. The trial was exclusively developed and performed at the facilities of the University of Extremadura, Spain, with the approval of the Committee on Biomedical Ethics of the University and following the updates of the Declaration of Helsinki.

\section{Study design}

A research assistant randomized participants to either the EG or CG, according to a random number table (Table 1) and assigned a code number to each participant. Another research assistant, different from the one who supervised the treatment and analyzed data, administered the questionnaires used to gather information at baseline and after 3 and 8 months of the programme.

\section{Interventions}

Usual care and the addition of a water-based exercise programme were compared in the $C G$ and $E G$, respectively. The usual care included standard medical attention in the public system (hospital and outpatient clinic including primary care) and the social support of the local FM association. This care could be considered the average standard of care or better for patients with $\mathrm{FM}$.

The intervention added an exercise programme in a in a waisthigh pool of warm water $\left(33^{\circ} \mathrm{C}\right)$. A qualified exercise leader instructed and trained the intervention group three times a week for $1 \mathrm{~h}$ per session over a period of 8 months. Each session included 10 min of warming up with slow walking and easy movements of progressive intensity, $10 \mathrm{~min}$ of aerobic exercises at $60-65 \%$ of maximal heart rate, 20 min of overall

Figure 1

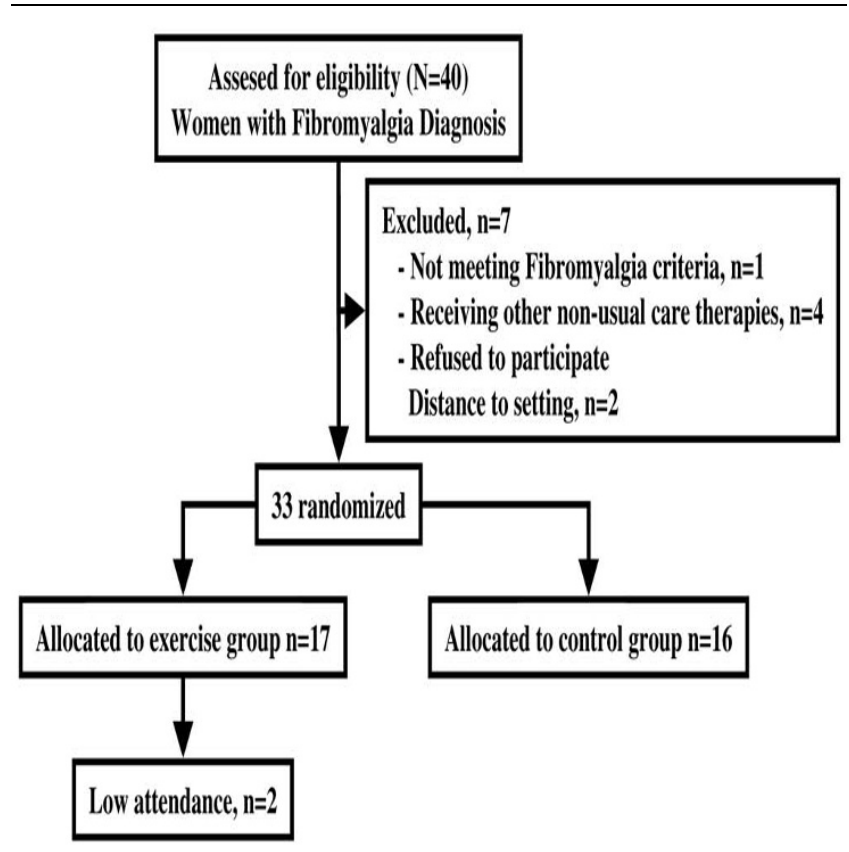

Flowchart outlining participation in the treatment. 
Table 1

\begin{tabular}{|c|c|c|c|}
\hline & Exercise group & Control group & p Value \\
\hline Age (years) a & $50.7(10.6)$ & $50.9(6.7)$ & 0.935 \\
\hline Body mass index $(\mathrm{kg} / \mathrm{m} 2)^{a}$ & $28.8(4.5)$ & $26.6(3.5)$ & 0.147 \\
\hline Duration of symptoms (years)a & $20.1(8.0)$ & $19.4(6.9)$ & 0.791 \\
\hline Number of tender points ( 1 to 18 points) ${ }^{a}$ & $16.9(1.8)$ & $17.2(1.3)$ & 0.563 \\
\hline Number of specific drugs (anti depressives, muscular relaxants, analgesics)a & $1.3(0.8)$ & $1.5(0.8)$ & 0.379 \\
\hline Employment status, $\mathrm{n}(\%): \mathrm{b}$ & & & 0.750 \\
\hline Blue collar & 8 (53.3) & $6(40.0)$ & \\
\hline White collar & 2 (13.3) & $3(20.0)$ & \\
\hline Unemployed & 5 (33.3) & $6(40.0)$ & \\
\hline Education level, n:b & & & 0.184 \\
\hline Unfinished studies & $1(6.7)$ & $1(6.7)$ & \\
\hline Primary school & $9(60.0)$ & $6(40.0)$ & \\
\hline Secondary school & $1(6.7)$ & $6(40.0)$ & \\
\hline University degree & $4(26.7)$ & 2 (13.3) & \\
\hline
\end{tabular}

aValues expressed as mean (SD), $p$ values from analysis of variance (ANOVA); b p values from analysis of Chi-square.

mobility and lower limb strength exercises using water resistance, another set of $10 \mathrm{~min}$ of aerobics at $60-65 \%$ of maximal heart rate, and 10 min of cooling down with low intensity exercises. Heart rate was monitored using a pulse meter (Polar Accurex Plus, Kempele, Finland). During this 8-month period participants in the control group continued their daily activities, which did not include any form of physical exercise similar to that in the programme. This programme was designed without reference to any explicit behavioral model or theory, and was intended as a pragmatic intervention that could be easily organized for a large population.

\section{Data collection}

Participants completed questionnaires, including the EuroQol $E Q-5 D$ health status instrument [17] at the beginning of the programme and after 3 and 8 months. During the same period, private and public health care was recorded, including hospital stays, drug usage, secondary and primary care appointments.

\section{Unit costs}

The expense and time needed for travel from the patient's residence to the rehabilitation pool varied, because this facility is a scarce health resource serving a large area. To allow for a range in such additional costs, we performed two economic analyses, one from a health service perspective and another from a societal perspective. The first perspective is recommended by the National Institute for Clinical Excellence (NICE) in the UK to inform decisions on health care policy for an expensive condition. This perspective could help to decide whether to finance the addition of the programme to the health system. The second perspective is recommended to consider the combination of the burden to the patient and the health care system. The unit costs are expressed in Euros $(€)$ based on prices in 2005 .

Costs were not adjusted or discounted for changes in currency value over time, as we focused solely on effects over less than 1 year. The programme's cost was calculated based on the following: salaries at the level for a university graduate, cost of staff to run the programme, salaries at minimum wage for the patient's time (based on the 2005 official bulletin of the regional government), cost of renting a pool at a university at public prices without a grant, public bus prices, and private external management costs of the programme (insurance, monthly retrievals from patients and withdrawals to employees). Health care prices (consultations, etc.) were based on the 2005 official bulletin of the regional government. Drug prices were obtained from the Spanish version of Vademecum International [18].

\section{Health outcomes}

The EQ-5D [17] was used to assess five dimensions of health related quality of life: (1) mobility, (2) self-care, (3) daily activities, (4) pain and discomfort, and (5) anxiety or depression. The scale for each dimension is from 1 to 3 (with 1 no problems, 2 some problems, and 3 extreme problems). Using a combination of these dimensions, a total of 243 possible health states exist. Each health state has been previously defined using the time trade-off method of utility analysis based on the response of a sample of the Spanish population [19]. This total score of utility was scaled from $1=$ fully functional quality of life to $0=$ death. The quality-adjusted life years 
(QALYs) that participants experienced over the 8-month period were estimated by calculating areas under health utility curves [20]. To avoid bias, data were adjusted by regression analysis for differences in baseline EQ-5D scores [21].

\section{Cost utility analysis}

First, we estimated the incremental mean costs of the waterbased programme and the mean QALYs added by the programme from a health care and societal perspective. Secondly, the incremental cost effectiveness ratio for the waterbased programme was calculated by dividing the incremental costs by incremental QALYs.

To report the uncertainty due to sampling variation, we calculated the 95\% confidence interval using the non-parametric bootstrapping technique (1,000 replicates re-sampled with replacement from treatment and control populations) and plotted a cost effectiveness acceptability curve [22,23]. This curve shows the probability that the intervention is cost effective compared with the alternative, across the range of values that decision makers are willing to pay to achieve an additional QALY. The "investment ceiling" is the level of spending that should not be exceeded, even assuming unlimited funding availability. For the health care system in Spain, the 2005 adjusted investment ceiling was set at $€$ 34,729/OALY [24]. Decision makers should compare this upper limit of acceptable payment with estimated incremental cost effectiveness ratios to determine whether a given treatment is cost effective relative to the alternatives.

For the health system and societal perspectives, seven sensitivity analyses were performed to explore the robustness of the estimates and how dependent the results were on estimates of participants' unit costs and efficacy. From the health system perspective, the first analysis examined the influence of participation rate in the programme as this could influence the productivity by affecting the number of participants per unit of time provided by the technician. A second analysis explored the variations due to the salary changes of the technician, since this is a major source of variability in economic studies [25]. From a societal perspective, in addition to two previous analyses the third analysis estimated the cost of increasing the mean distance (in terms of time spent and the number of bus tickets purchased) from the patient's residence to the rehabilitation pool. Finally, from both perspectives, the robustness of cost effectiveness was examined by exploring scenarios combining the influence of the variations in staff salary, rate of participation, distance to the facility and effectiveness, from the lowest to the highest limit of the 95\% confidence interval.

\section{Results \\ Costs}

Table 2 shows the incremental costs, to the health care system, and to society, of implementing the exercise programme. The main cost was associated with renting the pool and the difference between perspectives was mainly attributed to the cost of time spent for travel and the intervention programme. Table 3 shows the mean incremental cost per patient who participated in three sessions per week in a pool with a capacity for 20 persons. Participants in the EG and CG did not reported changes in the number of physician consultations (1 primary care visit per month; 0.3 specialist visit per month, and no hospitalizations). A total of 10 women in the EG and 5 in the $C G$ reported changes in medication. Seven women in the EG stopped their doses of medication of amitriptyline $(n=7)$, cyclobenzaprine for sleeping $(n=2)$ or paracetamol $(n=1)$. However, two of these seven women started to take ibuprofen and another began to take cyclobenzaprine. In the CG, three women stopped the doses of medication (hydroaltesona, ibuprofen and citalopram). Over the 8 months, the weekly cost of medication increased above baseline by $€ 5.4$ in each group as a whole; however, no remarkable incremental costs of intervention group compared to control group for medication or consultation were observed.

\section{Health outcome}

Table 3 shows that the water-based programme was associated with a greater increase in the EQ-5D utilities than the usual care during the first 3 months and this difference was preserved during the subsequent 5 months.

\section{Cost utility analysis}

Table 3 shows the cost utility analyses from both perspectives. From the health service perspective, the Spanish Health System Efficiency Threshold was set at $€ 23,153 /$ QALY for 8 months by multiplying the published threshold of 34,729 for 12 months by 8/12 [24]. From the health service perspective, each additional QALY gained by the exercise group cost in average $€ 3,947$. However, the cost effectiveness acceptability curves (Figure 2) showed a $95 \%$ probability that the addition of the water-based programme is a cost effective strategy if the ceiling of inversion is $€ 14,200 /$ QALY and a $97.5 \%$ probability if the ceiling is set at $€ 21,233 /$ QALY.

From a societal perspective, the mean cost per QALY was $€$ 7,878 /QALY and there is a $95 \%$ probability that the addition of the aquatic training is cost effective if the ceiling of inversion is $€ 28,300 /$ QALY. A $97.5 \%$ probability requires an inversion higher than $€ 42,000 / Q A L Y$.

\section{Sensitivity analysis}

The sensitivity analyses are presented in Table 4. These analyses showed the robustness of the conclusion that the waterbased therapy is the best alternative compared to usual care to the variations of staff salaries and the number of participants attended per session. Nevertheless, in the worst case scenario, with a combination of minor improvements in cost utilities and a low number of clients per session, warm water exercise would be inefficient (more than $€ 23,000 / Q A L Y$ ) from both perspectives. The main source of variation was 
Table 2

Incremental cost of the exercise programme compared to usual care

\begin{tabular}{|c|c|c|c|}
\hline Concept & Unita & Over 8 months $(€)$ & Total $(€)$ \\
\hline \multicolumn{4}{|l|}{ Health system costs: } \\
\hline \multicolumn{4}{|l|}{ Personnel:b } \\
\hline Sport technician & $€ 9 / \mathrm{h}$ & 1,092 & \\
\hline Nurse & $€ 6.5 / h$ & 788 & \\
\hline Insurances and prevention & $€ 350$ & 350 & \\
\hline Facilities (renting pool and safeguards) & $€ 55 / \mathrm{h}$ & 5335 & \\
\hline Management & $€ 24 /$ month & 192 & \\
\hline Medication (total health system perspective) ${ }^{c}$ & Drug price & 0 & 7,757 \\
\hline \multicolumn{4}{|l|}{ Additional societal costs: } \\
\hline Time spent in therapy & $€ 2.15 / h$ & 3,135 & \\
\hline Time spent in displacements and clothing & $€ 2.15 / h$ & 3,135 & \\
\hline Travel costs (bus tickets) & $€ 0.5 /$ ticket & 1,455 & \\
\hline Sub-total, societal additional costs & & & 7,725 \\
\hline Total societal (additional costs and health system costs) & & & 15,482 \\
\hline
\end{tabular}

aPublic cost in $€$ in 2005 ; bsalary over 8 months $=$ number of units $\times 13 \mathrm{~h} /$ month $\times 9.33$ monthly salaries; c no relevant incremental costs between groups were found. The weekly cost of medication increased $€ 5.4$ from baseline in each group.

observed by changing the staff salaries, effectiveness in QALYs, and the distance to the facility.

\section{Discussion \\ Principal findings}

Previous studies reported the efficacy of aquatic training on patients with fibromyalgia [11-15,26,27] and the cost-utility of a 2.5 week spa treatment [28], but to our knowledge the present study is the first to report cost-utility. The major finding of this study was that the water-based programme was a costeffective addition to usual care from both health system and societal perspectives. More precisely, an investment in this aquatic training for a similar population (sedentary women with FM) has a greater than $95 \%$ probability of being efficient according to the investment ceiling in Spain.

\section{Strengths and weakness}

The acceptable efficiency threshold, investment ceiling or maximum willingness to pay for each gained QALY varies among countries or societies because of differences in salaries, priorities, etc. The current study applied the commonly lower threshold of $€ 34,729$ ( $€ 23,153$ for 8 months) used in the Spanish literature [24], but similar conclusions about the efficiency of the addition of aquatic training to usual care could be achieved using the threshold updated to year 2005 (annual inflation of 5\%) often reported in American literature (\$50,000 to $\$ 60,000)$ or Dutch literature ( $€ 28,940)$ [29].
The retention rate of patients in the our programme (88\%) was similar to rates previously reported in community group-based exercise programmes in fibromyalgia (70-90\%); however, aquatic training programmes usually report lower retention rates (55-75\%) [9]. The social support provided by physicians, research teams, and peers with FM from the local association may have contributed to this high retention rate and the improvement in the psychosocial dimensions of health related quality of life and QALY in the exercise group. Particularly, the patient's affiliation with the local FM association brought them additional care (social support, information, etc.) in comparison to what is offered by the Public Health Care System. In this sense, the care received by the control group could be considered better than usual. By contrast, care that combines the study programme with other therapies may be even better than the programme alone. This issue could not be addressed in the current study because patients were excluded if they used other therapies (standardized behavioral or physical therapies such as massages, etc.).

The small sample size led us to use non-parametric bootstrapping techniques to treat the confidence intervals and probability curve. Health economists recommend bootstrapping techniques, rather than standard deviation-based methods, for treating the uncertainty of cost-effectiveness ratios $[22,23,30$ 33]. The small sample, the fact that subjects were selfselected according to bioethics requirements and the catch- 
Table 3

Cost-utility analyses

\begin{tabular}{|c|c|c|}
\hline Alternatives & Usual care & Usual care plus exercise \\
\hline EQ-5D utility at baseline ${ }^{a}$ & $0.331(0.150$ to 0.511$)$ & $0.316(0.162$ to 0.470$)$ \\
\hline EQ-5D utility at 3 months $^{a}$ & $0.334(0.175$ to 0.494$)$ & 0.582 (0.434 to 0.729$)$ \\
\hline EQ-5D utility at 8 months $^{a}$ & $0.334(0.175$ to 0.493$)$ & 0.528 (0.380 to 0.675$)$ \\
\hline QALY over 8 months ${ }^{b}$ & $0.002(-0.087$ to 0.091$)$ & $0.133(0.034$ to 0.231$)$ \\
\hline QALY difference vs. usual care & & $0.131(0.011$ to 0.290$)$ \\
\hline \multicolumn{3}{|l|}{ Health system perspective: } \\
\hline Incremental cost/person $(€)$ & & 517 \\
\hline Cost-utility $(€ / Q A L Y) c$ & & $3,947(1,782$ to 47,000$)$ \\
\hline \multicolumn{3}{|l|}{ Societal perspective: } \\
\hline Incremental cost/person $(€)$ & & 1,032 \\
\hline Cost-utility (€/QALY) ₹ & & $7,878(3,559$ to 93,818$)$ \\
\hline
\end{tabular}

QALY, quality adjusted life year.

aMean (95\% confidence interval) estimated by analysis of covariance with adjustment for baseline EQ-5D score and then rounded to 3 significant figures; bmean ( $95 \%$ confidence interval) using the area under the curve technique; cmean (95\% confidence interval estimated by bootstrapping) using the area under the curve technique.

ment throughout local patient associations may limit the generalization of our findings to treatment of less motivated patients.

\section{Use of health care}

The current study did not find any evidence for decreased use of health care services during the study period. However, the lack of change in the ratio of frequency (consultations/month) can be explained partially by the limits of supply and the management of free appointments in the general practices of the National Health System in Spain. A study in a non-limited supply setting could address the question of whether an aquatic programme could reduce the use of other health care services.

Figure 2

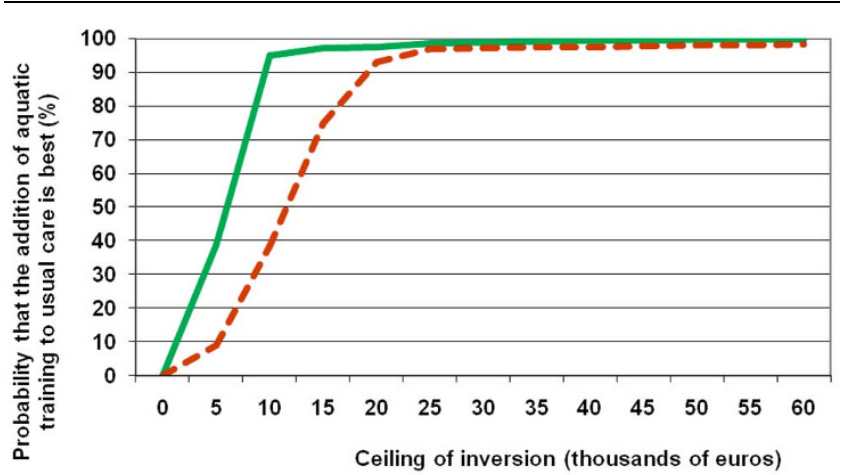

\section{Health System Analysis $\quad$----Societal Analysis}

Probability curves that the addition of the aquatic training to usual care is cost-effective.
The increase in the medication cost in both groups may be partly explained because the perception of pain is slightly increased in the summer in persons with fibromyalgia [34]; with a change in the average temperature in Extremadura from $14^{\circ} \mathrm{C}$ at baseline to $22^{\circ} \mathrm{C}$ at the end of programme.

By contrast, the aquatic training in facilities with warm water was a cost-effective addition to usual care but it was not compared to other physical therapies that could reduce geographic inequalities (e.g., land-based therapies such as lowimpact aerobics, walk-based exercise, tai chi, etc.) because their facilities are cheaper and easier available in more municipalities.

\section{Conclusion}

An 8-month aquatic training programme is a cost-effective addition to the usual care provided by the Public Health System. This programme enhances the health-related quality of life in women with FM. However, the characteristics of facilities (distance from patients' homes and the number of patients that can participate per session) are major determinants that have to be considered before a health manager decides to invest in such a programme.

\section{List of abbreviations}

$\mathrm{CG}=$ control group; $\mathrm{EG}=$ exercise group; $\mathrm{FM}=$ fibromyalgia; $\mathrm{QALY}=$ quality-life adjusted-years.

\section{Competing interests}

The authors declare that they have no competing interests. 
Health system analysis:

Number of participants per pool session:

30\% lower (10 patients/group)

$30 \%$ higher (20 patients/group)

Salary of personnel:

30\% lower (monitor and nurse)

$30 \%$ higher (monitor and nurse)

No additional salary of nurse

Best case scenario of salary, participation and effectiveness ${ }^{b}$

Societal analysis:

Number of participants per pool session:

30\% lower (10 patients/group)

Salary of personnel:

30\% lower (monitor and nurse)

Distance to facilities per session:

Near (without bus ticket and $1.5 \mathrm{~h}$ spent)

QALY, quality adjusted life year.

aFrom the Spanish Health System, the cost-utility ratio threshold was set at $€ 23,153 / Q A L Y$ for 8 months in 2005; bpool rental + participation 20 persons per group + QALY differential at higher limit of 95\% confidence interval; ' salary $30 \%$ higher (monitor and nurse) + participation 10 persons per group + QALY differential at lower limit of $95 \%$ confidence interval.

\section{Authors' contributions}

NG was involved in the conception, planning and design of the study, as well as the acquisition, analysis, and interpretation of data, and writing of the manuscript. PTC was involved in the acquisition of data, analysis and assisting in the writing of manuscript. Both authors read and approved the final manuscript.

\section{Acknowledgements}

Thanks to Yolanda Garcia for her technical support as research assistant. The study was supported by the European Social Funds and the Government of Extremadura, Spain (2PR02B017 and Health Department).

\section{References}

1. Wolfe $F$, Smythe HA, Yunus MB, Bennett RM, Bombardier C, Goldenberg DL, Tugwell P, Campbell SM, Abeles M, Clark P, Fam AG, Farber SJ, Fiechtner JJ, Franklin CM, Gatter RA, Hamaty D, Lessard J, Lichtbroun AS, Masi AT, Mccain GA, Reynolds WJ, Romano TJ, Russell IJ, Sheon RP: The American College of
Rheumatology 1990 Criteria for the Classification of Fibromyalgia. Report of the Multicenter Criteria Committee. Arthritis Rheum 1990, 33:160-172.

2. Wolfe F, Anderson J, Harkness D, Bennett RM, Caro XJ, Goldenberg DL, Russell IJ, Yunus MB: A prospective, longitudinal, multicenter study of service utilization and costs in fibromyalgia. Arthritis Rheum 1997, 40:1560-1570.

3. Carmona L, Ballina J, Gabriel R, Laffon A: The burden of musculoskeletal diseases in the general population of Spain: results from a national survey. Ann Rheum Dis 2001, 60:1040-1045.

4. White KP, Speechley M, Harth M, Ostbye T: The London Fibromyalgia Epidemiology Study: the prevalence of fibromyalgia syndrome in London, Ontario. I Rheumatol 1999, 26:1570-1576.

5. Boonen A, van den Heuvel R, van Tubergen A, Goossens M, Severens JL, van der Heijde D, van der Linden S: Large differences in cost of illness and wellbeing between patients with fibromyalgia, chronic low back pain, or ankylosing spondylitis. Ann Rheum Dis 2005, 64:396-402.

6. Doron Y, Peleg R, Peleg A, Neumann L, Buskila D: The clinical and economic burden of fibromyalgia compared with diabetes mellitus and hypertension among Bedouin women in the Negev. Fam Pract 2004, 21:415-419. 
7. White KP, Speechley M, Harth M, Ostbye T: The London Fibromyalgia Epidemiology Study: direct health care costs of fibromyalgia syndrome in London, Canada. J Rheumatol 1999, 26:885-889.

8. Kivimaki M, Leino-Arjas $P$, Kaila-Kangas L, Virtanen M, Elovainio M, Puttonen S, Keltikangas-Jarvinen L, Pentti J, Vahtera J: Increased sickness absence among employees with fibromyalgia. Ann Rheum Dis 2007, 66:65-69.

9. Koulil SV, Effting M, Kraaimaat FW, Lankveld WV, Helmond TV, Cats $\mathrm{H}$, van Riel $\mathrm{P}$, de Jong $\mathrm{A}$, Haverman J, Evers A: A review of cognitive behaviour therapies and exercise programmes for fibromyalgia patients: state of the art and future directions. Ann Rheum Dis 2006. doi:10.1136/ard.2006.054692

10. Mannerkorpi K: Exercise in fibromyalgia. Curr Opin Rheumatol 2005, 17:190-194.

11. Gusi N, Tomas-Carus $P$, Hakkinen A, Hakkinen K, Ortega-Alonso $A$ : Exercise in waist-high warm water decreases pain and improves health-related quality of life and strength in the lower extremities in women with fibromyalgia. Arthritis Rheum 2006, 55:66-73.

12. Jentoft ES, Kvalvik AG, Mengshoel AM: Effects of pool-based and land-based aerobic exercise on women with fibromyalgia/chronic widespread muscle pain. Arthritis Rheum 2001, 45:42-47.

13. Altan L, Bingol U, Aykac M, Koc Z, Yurtkuran M: Investigation of the effects of pool-based exercise on fibromyalgia syndrome. Rheumatol Int 2004, 24:272-277.

14. Assis MR, Silva LE, Alves AM, Pessanha AP, Valim V, Feldman D, Neto TL, Natour J: A randomized controlled trial of deep water running: clinical effectiveness of aquatic exercise to treat fibromyalgia. Arthritis Rheum 2006, 55:57-65.

15. Redondo JR, Justo CM, Moraleda FV, Velayos YG, Puche JJ, Zubero JR, Hernandez TG, Ortells LC, Pareja MA: Long-term efficacy of therapy in patients with fibromyalgia: a physical exercise-based program and a cognitive-behavioral approach. Arthritis Rheum 2004, 51:184-192.

16. Tomas-Carus $P$, Hakkinen $A$, Gusi $N$, Leal $A$, Hakkinen $K$, OrtegaAlonso A: Aquatic training and detraining on fitness and quality of life in fibromyalgia. Med Sci Sports Exerc 2007, 39:1044-1050.

17. Herdman M, Badia X, Berra S: EuroQol-5D: a simple alternative for measuring health-related quality of life in primary care. Aten Primaria 2001, 28:425-430.

18. Vademecum [http://www.vademecum.es]

19. Badia X, Roset M, Montserrat S, Herdman M, Segura A: The Spanish version of EuroOol: a description and its applications. European Quality of Life scale. Med Clin (Barc) 1999, 112(Suppl 1):79-85.

20. Matthews JN, Altman DG, Campbell MJ, Royston P: Analysis of serial measurements in medical research. BMJ 1990, 300:230-235

21. Manca A, Hawkins N, Sculpher MJ: Estimating mean QALYs in trial-based cost-effectiveness analysis: the importance of controlling for baseline utility. Health Econ 2005, 14:487-496.

22. Fenwick $E$, Byford $S$ : A guide to cost-effectiveness acceptability curves. Br J Psychiatry 2005, 187:106-108.

23. Willan AR: On the probability of cost-effectiveness using data from randomized clinical trials. BMC Med Res Methodo/ 2001, $1: 8$.

24. Sacristan JA, Oliva J, Del Llano J, Prieto L, Pinto JL: What is an efficient health technology in Spain? Gac Sanit 2002, 16:334-343.

25. Sevick MA, Dunn AL, Morrow MS, Marcus BH, Chen GJ, Blair SN: Cost-effectiveness of lifestyle and structured exercise interventions in sedentary adults: results of project ACTIVE. Am J Prev Med 2000, 19:1-8.

26. Mannerkorpi K, Ahlmen M, Ekdahl C: Six- and 24-month followup of pool exercise therapy and education for patients with fibromyalgia. Scand J Rheumato/ 2002, 31:306-310.

27. Mannerkorpi K, Nyberg B, Ahlmen M, Ekdahl C: Pool exercise combined with an education program for patients with fibromyalgia syndrome. A prospective, randomized study. J Rheumatol 2000, 27:2473-2481.

28. Zijlstra TR, Braakman-Jansen LM, Taal E, Rasker JJ, van de Laar MA: Cost-effectiveness of Spa treatment for fibromyalgia: general health improvement is not for free. Rheumatology (Oxford) 2007, 46:1454-1459.
29. van den Hout WB, Tijhuis GJ, Hazes JM, Breedveld FC, Vliet Vlieland TP: Cost effectiveness and cost utility analysis of multidisciplinary care in patients with rheumatoid arthritis: a randomised comparison of clinical nurse specialist care, inpatient team care, and day patient team care. Ann Rheum Dis 2003, 62:308-315.

30. Coupe VM, Veenhof C, van Tulder MW, Dekker J, Bijlsma JW, van den Ende $\mathrm{CH}$ : The cost-effectiveness of behavioural graded activity in patients with osteoarthritis of hip and/or knee. Ann Rheum Dis 2006. doi:10.1136/ard.2006.054478

31. Briggs A, Fenn P: Confidence intervals or surfaces? Uncertainty on the cost-effectiveness plane. Health Econ 1998 7:723-740.

32. Lothgren M, Zethraeus N: Definition, interpretation and calculation of cost-effectiveness acceptability curves. Health Econ 2000, 9:623-630

33. Epps H, Ginnelly L, Utley M, Southwood T, Gallivan S, Sculpher M, Woo $P$ : Is hydrotherapy cost-effective? A randomised controlled trial of combined hydrotherapy programmes compared with physiotherapy land techniques in children with juvenile idiopathic arthritis. Health Technol Assess 2005, 9:iii-iv. ix-x, 159.

34. Hawley DJ, Wolfe F, Lue FA, Moldofsky H: Seasonal symptom severity in patients with rheumatic diseases: a study of 1,424 patients. J Rheumato/ 2001, 28:1900-1909. 